\section{É possivel os Distritos de Educação e Cultura estarem a serviço da transformação}

político-ideologico. O segundo fato ligase a uma tentativa de coletivizar tais reflexôes, estendendo-se não somente aos psicólogos ou a outros profissionais que trabalham nos distritos de educaçăo e cultura, mas a todos que tem o compromisso com uma educaçăo transformadora que possibilite um efetivo desenvolvimento de nossa cidadania.

\section{Os Distritos de Educação e Cultura têm uma História}

No Rio de Janeiro os distritos de educaçăo e cultura criados em 1975, na gestăo da secretária municipal de educação Terezinha Saraiva (1), funcionam em nível intermediário, dando "apoio" pedagogico e administrativo às unidades escolares de uma determinada região administrativa, sendo responsáveis pela execução da política planejada pela Secretaria Municipal de Educação.

A criação dos distritos de educaçãoe cultura inscreve-se num contexto histórico brasileiro em que a ditadura militar - instaurada com o golpe de 1964 - se exercia da forma mais feroze violenta. Passam a estar presentes em toda a política educacional dois grandes eixos: o desenvolvimentista e o da segurança nacional (2). Daí, a organização educacional se estruturar para que um efetivo controle pudesse ser melhor exercido e năo para que a produtividade - tăo alardeada - fosse maior. Tal produtividade baseia-se, principalmente, em dois princípios: o tecnicismo e a divisa social do trabalho que tăo "bons resultados" apresentaram nas fábricas. Assim, desde o inf́cio da década de 70 no Brasil, inicia-se um forte movimento onde săo enfatizadas a "modemizaçăo" da escola e a "tecnificaçæo" da educação.

A pedagogia tecnicista aponta para a necessidade de se redimir o sistema educacional de sua ineficiência e inoperância. Daí, importam-se principalmente dos Estados Unidos (3), técnicas que haviam produzido "otimos" resultados no desempenho industrial. Tambêm aqui, o "desempenho educacional" passa a ser visto da mesma forma; isto $\hat{\varepsilon}$, enfatizados os pressupostos positivistas da cientificidade, objetividade, racionalidade e neutralidade.

De tais pressupostos decorre o parcelamento do trabalho pedagogico com a hegemoniados"especialistas em educacto". Esses "donos do saber", considerados "iluminados" e "competentes" trazem a secundarizaç $x$ o mesmo a inferiorizacto do saber 'dos professores (4). $O$ acesso às funçðes tócnicas passa a ser vistas como ascençăo profis-
(M. Foucault - "A Verdade e As Formas Juridicas") poder judiciario. A todo momento se pune e se recompensa, se avalia, se classifica, se diz quem es o melhor, quem é o pior." \section{psicólogas desenvolvendo há anos tra-} balhos em distritos de educaçăo e cultura. Isto é, a nossa necessidade de colocar no papel o que há algum tempo já temos repensado sobre nossa atuaçấ sobre tais órgås e seu significado 


\author{
A pedagogia tecnicista aponta \\ para a necessidade de se redimir \\ o sistema educacional de sua \\ ineficiência e inoperância. Daí, \\ importam-se principalmente dos \\ Estados Unidos, técnicas que \\ haviam produzido "ótimos" \\ resultados no desempenho \\ industrial. Também aqui, o \\ "desempenho educacional" \\ passa a ser visto da mesma \\ forma; isto é, enfatizados os \\ pressupostos positivistas da \\ cientificidade, objetividade, \\ racionalidade e neutralidade.
}

trativa do E-DEC está ligada a departamientos e assessorias correspondentes que the direcionam a atuagão. E o que muito cedo se percebeu, é que estas direçбes chegavam isoladas, o que nos fez crer que as assessorias entre si e em relação aos departamentos integravam seus planejamentos e, muito mais, possuiam até ideologias e filosofias contraditórias. Desta forma, as diretrizes da SME chegavam às equipes do EDEC fragmentadas, o que produzia trabalhos também fragmentados e estanques. Assim eram levadas às escolas e assim eram cobradas (6).

Diante desse quadro, posteriormente, algumas reformulaçoes foram feitas numa tentativa de se romper com a fragmentaça e o isolamento das diferentes equipes pedagógicas dos distritos de educaçåo e cultura. A nosso ver ficou-se simplesmente na tentativa, pois apesar da formação de uma única equipe pedagogica (7), as orientaçðes da Secretaria Municipal de Educaçăo e a prática dos profissionais ainda continuaram vinculadas a trabalhos que se referiam a atuaçoes em campos especificos. Os discurso oficial da época passa a criticar os especialismos e corporativismos; entretanto, a nosso ver, mais uma vez se busca um culpado. Se antes eram 0 aluno e sua familia os responsáveis pela inoperância na aprendizagem, a partir de 1984 passam os professores e, logo depois os "especialistas" a serem apontados como osprin. cipais fatores da ineficiência escolar.

Pensamos que a crítica aos especialismos é fundamental para um avanço na democratizaçăo das relaçóes de poder dentro e fora da escola. Entretanto, o discurso oficial torna-se parcial, incompleto e cheio de lacunas, na medida em que ao culpabilizar os profissionais em si mesmos - individualmente - combatendo-os simplesmente, 'deixa de relacionar a prática desenvolvida como produto da própria divisāo social do trabalho no interior da escola. Cria-se, com isso, mais resistência do que possibilidades efetivas de transformaçăo de açāo até entāo desenvolvida. Possibilidades de transformação que se dão quando os profissionais se percebem implicados politicamente com seu trabalho, rompendo não só com uma atuação corporativista como também com os pressupostos tecnicistas presentes no seu cotidiano.

Contra tais marcas e apesar dessa realidade, muitos profissionais que nestes últimos anos atuaram nos distritos de educaçāo e cultura, orientaram seus trabalhos. Iniciativas no sentido de uma maior aproximação com os problemas e dificuldades encontrados no dia a dia 
da escola foram tentadas. Entretanto, o que verificamos é ainda um grande distanciamento entre os três níveis que compoem a estrutura da Secretaria Municipal de Educaçāo. A escola - o chamado nível local - que deveria ser o grande palco, o espaço principal onde se planejariam e se executariam as tarefas pertinentes à educaçð̄o, toma-se um local de mera execução, isolada em sua própria realidade. Os níveis privilegiados onde se planeja são outros: o central e o intermediário. Este, representado pelos distritos de educação e cultura têm a tarefa de retransmitir as diretrizes oriundas dos departamentos e assessorias do nível central, cabendo a este o papel principal dentro da estrutura. Privilegia-se aqueles que, "escolhidos" pelos que planejam e dirigem o processo, passam a constituir a esfera daqueles que "pensam de forma competente" $e$, por isso, têm o poder de dizer a primeira palavrae, namaioria das vezes, a última a respeito de decisסes a serem tomadas.

No momento em que começamos a escrever este artigo, esteve em curso mais uma reformulaçăo na estrutura dos distritos de educaçáo e cultura. Ainda que sua publicação não tivesse saído no Diário Oficial do município, tais mudanças eram transmitidas pelas chefias aos profissionais que trabalham nesses locais.

$O$ discurso oficial, buscando enfatizar a necessidade de diminuição dos técnicos que atuam nesse nível, propōe uma nova linha de ação (8) que, a nosso ver, nå diminui o quantitativo desses profissionais. Simplesmente os redistribui - como é o caso dos psicólogos rearrumando o funcionamento de tal espaço.

Tais modificaçôes trazem em seu bojo sérias contradiçðes: a principal seria a fragmentação do trabalho neste nível intermediário.

Desde 1983, oficialmente se criticava a dispersåo e o isolamento das equipes técnico-pedagógicas dos distritos de educação e cultura e, por isso, instituiu-se - como já assim falamos uma única equipe. Hoje, a nosso ver, ocorre um retrocesso, ou seja, separa-se o pedagógico do comunitário e dentro do próprio pedagogico diferenciam-se as atuaçōes junto às escolas de $1^{2} \mathrm{seg}$ mento e as de $2^{\circ}$ segmento (9). Reforçase a divisão que já em 1983 denunciávamos, ao apontarmosoprofundo fosso que continuava existindo entre o funcionamento - tanto pedagógico, quanto administrativo - das escolas de C.A. à $4^{\text {I }}$ série (escolas primárias) e as de $5^{\text {a }}$ a $8^{2}$ séries (antigos gínásios), assim como suas relaçotes com os distritos de educação (10).

“... Os antigos ginásios rejeitavam qualquer trabalho vindo do E-DEC, o que pode ser explicado pelo sentimento de perda da autonomia, enquanto que nas escolas primárias ocorria uma extrema dependência para com o E-DEC e que era reforçada por este, o que gerou por vezes, um processo de infantilização.

...Nas escolas onde existiam os dois segmentos, via de regra passaram a existir também duas escolas, com os dois grupos de professores nå se integrando..."(11).

Nesta reformulaçāo as equipes sāo constituidas por diferentes profissionais, numa tentativa - segundo discurso oficial - de se formar grupos multidisciplinares. Entretanto, tal arrumação traz uma outra contradição - enquanto of icialmente se questiona os especialismos criam-se, na prática, novos especialistas. Ou seja, aqueles que trabalharão somente com os aspectos pedagógicos e os que se encarregarão do comunitário, como é o caso das assis- tentes sociais e outros profissionais

O próprio tipo de trabalho a ser desenvolvido pela equipe pedagógica acompanhamento às escolas -, através de "instrumentos" que sāo preparados pela Secretaria Municipal de Educaçăo, nos lembra muito a pedagogia tecnicista e o tāo decantado desempenho educacional.

Percebemos que as reestruturaçóes citadas somente têm levado em consideração o aspecto burocrático-administrativo, embora venham calcadas em cima de avaliaçōes críticas ao funcionamento da Secretaria Municipal de Educação e Cultura. $O$ eixo político que sustenta a base de tais avaliacores. desaparece quando da sua implantação, tornando-se predominante o tecnicismo, a crença na neutralidade e na competência.

Após um ano e meio desta última reformulaçāo,constatamos que a integração desses serviços nāo ocorreu e, apesar do nivel central da Secretaria Municipal de Educação colocar esse objetivo como uma de suas prioridades, a prática exercida pela SME não contribui para avançar nesse aspecto.

As análises feitas com relaçăo "às dificuldades de integração", muitas vezes incorrem no "equívoco" de responsabilizar individualmente os profissionais, sem considerar que reformulaçöes organizacionais não são meros instrumentos administrativos. Nesse momento (1991), a SME sinaliza com mais uma reformulação sem, contudo, discuti-la com o coletivo de seus profissionais.

Consideramos que, como psicólogos que somos, implicados com a educação e com a construçāo do "fazer" realmente coletivo, é nossa tarefa e de outros profissionais envolvidos com essas questð̄es contribuir para a "desnaturalização" desses movimentos institucionais. 
Pelo fato de nāo se analisar em profundidade os problemas, datando-se historicamente, enfatiza-se somente os aspectos burocrático-adiministrativos, passando-se a crença que tais reformulaçóes possam servir a alguma mudança.

Entendemos que pela própria marca que os distritos de educaçāo e cultura trazem em sua origem, voltada para a fiscalizaçăo e o controle, a luta daqueles que acreditam na transformação, será a luta por sua extinção. É politicamente conservador, num momento em que em nível nacional se rejeita todos os aparatos autoritários - criados para se exercer um poder mais eficaz - defender a existência dos distritos de educaçăo e cultura. Acreditamos ser muito mais produtivo a atuação direta de todos os profissionais lotados nesse órgào nas unidades escolares. Af sim, precisamse de mais recursos humanos.

Defendemos que somente socializando-se tal debate, através de uma política de pessoal mais voltada para as necessidades da escola pública, se poderia enfrentar realisticamente a transformaçāo do sistema educacional. Com isso, se poderia evitar casuísmos locais, como a simples dispensa e redistribuição de técnicos.

Caminhariamos, então, para que entre todos os profissionais da educaçāo dos diferentes níveis houvesse uma maior democratização nas relaçōes de poder; podendo-se coletivamente avançar no sentido de formar profissionais efetivamente implicados politicamente com seu trabalho.

Setembro / 1991

\section{III) Algumas Conclusões}

"Avaliar deve ser um processo na totalidade da prática escolar. Somente uma prática de avaliação que se abra para uma participação mais ampla poderá ser democrática. Torna-se necessário, entāo, uma atuação de todos os envolvidos na comunidade escolar, e que, ao avaliar seus alunos, o professor esteja avaliando o seu proprio trabalho. A instituiçāo deve ser também avaliada e questionada de tal forma que cada momento daavaliaçāo seja um momento de redefinição da ação pedagogica na direção dos objetivos que se espera alcançar."

(proposta curricular da SME, 1988)

Esta última reestruturação ocorreu no momento em que a própria SME tentava colocar em prática uma nova proposta curricular que tem como pressupostos filosoficos a construção de novos saberes através do debate coletivo em todos os níveis. Por que tantas contradiçסes?

Acreditamos que tais lutas são inerentes a todas as instituiç̋es, que não são em si monolíticas. Diferentes correntes existem e, no embate, algumas mais conservadoras se sobrepðem e, no momento, pensamos ser isso o que esteja ocorrendo.

\section{Notas}

(I) - Ano em que houve a fusāo do Estado do Rio de Janeiro com o Estado da Guanabara.

(2) - Tal direcionamento torna-se oficial e hegemônico a partir da decretaçāo do Ato Institucional $n^{2} 5$, em dezembro de 1968.

(3) - País onde o capitalismo monopolista se encontrava mais desenvolvido.

(4) - Sobre o "discurso da competência" ver alguns trabalhos de Marilena Chaui como: "Cultura e Democracia: o discurso competente e outras falas" $e$ "O que é ser Educador hoje? Da Arte à Ciência: a morte do educador."

(5) Psicólogos e Assistentes Sociais foram impedidos de permanecer atuando mas escolas. Supervisores e Orientadores excedentes, for am para oulras unidades ou compor as equipes dos $D E C s$.

(6) Coimbra, Cecília Maria B., Vas. concelos, Ceres D. e Travassos, Vera $L$ Lucia de $O$. - "É Revendo que se Repensa" - Rio de Janeiro - pp. 2,3-1983.

(7) Em 1984, quando da reestruturação dos Distritos de Educação e Cultura e da própria Secretaria Municipal de Educaçäo, as várias equipes técnicopedagógicas foram agrupadas numa única: o Serviço Técnico de Assuntos Educacionais (STAE).

(8) A reestruturaçăo (final de 1989) criou três Serviços separados: Serviço de Assuntos Administrativos, o de Assuntos Educacionais $e$ o de Assuntos Comunitarios.
(9) O Serviço de Assuntos Pedagógicos terá duos equipes: uno trabalhorá com as escolos de pré-escolar à $4^{4}$ série e outro ficará com as de $5^{a}$ a $8^{a}$ sérias.

(I0) Em 1975, quando se deu a fusão do Estado do Rio de Janeiro com o Estado da Guanabara e a criaçăo dos $D E C s$, os ensinos primário e secundário passaram a ser organizados da seguinte forma: $1^{\circ}$ Grau, composto de $1^{\circ}$ (pré. escolar à $4^{\circ}$ série $)$ e $2^{\circ}$ segmento $\left(5^{\circ}\right.$ à $8^{\circ}$ séries). $2^{\circ}$ Grau

(11) Coimbra, Cecília Mario B., et alli-op. cit.p. 21

\section{Bibliografia}

1. CHAUI, Marilena - Cultura e Demacracia: $O$ discurso competente e outras falas - SP, Ortez, 1989.

2.- $O$ que $e$ ser educador hoje? Da Arte à Ciência : a morte do educador in Brandāo, C. R, - Educodor: Vida e Morte - RJ - Graal - 1982.

3_____Conformismo e Resistencia - SP, Brasiliense, 1986.

4.COIMBRA, Cecília Maria B. - Os Anos 70 no Brasil e Algumas Teorias Educacionais Hegemômicas - Doutorada na USP, 1989, mimeogr.

S. FOCAULT, Michel - A Verdade e as Formas Juridicas - RJ Cadernos da

PUC - 1979. 